\title{
Effect of Pathogenesis-Based Individualized Thrombectomy on Treatment Result and Prognosis of Acute Intracranial Large-Artery Occlusion Patients
}

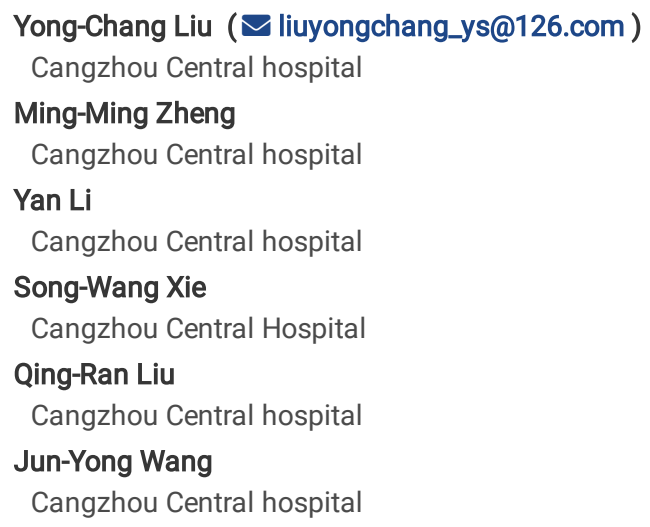




\section{Abstract}

Background

To explore the effect and prognosis of individualized thrombus removal methods based on different pathogenesis.

Methods

151 patients with acute cerebral infarction who were admitted to the hospital for intracranial artery interventional thrombus removal from January 2018 to November 2019 were selected as the research objects. Patients in the experimental group selected different thrombectomy methods based on medical history, pathogenesis, and cerebrovascular angiography results. Aspiration and embolization are the first choice for embolism, and stent embolization is the first choice for vascular stenosis. Compare the medical history, admission NHISS score, the time from the end of cerebral angiography to recanalization, the number of thrombus removal, MRS score at 3 months, complications, etc .

Results

There was no statistical difference in the basic data of the three groups. The time from the end of angiography to recanalization in the control group was significantly longer than that in the experimental suction group. There was a statistical difference between the control group and the experimental stent group in one-time thrombus removal opening rate $(P=0.048)$. The vascular recanalization rate was statistically different among the three groups $(P=0.611)$. The good prognosis rates of the experimental stent group and the experimental suction group were higher than those of the control group.

Conclusion

The first choice for patients with cerebral infarction caused by embolization can shorten the recanalization time. Stent removal is the first choice for patients with cerebral infarction caused by atherosclerosis, which can increase the opening rate of thrombus removal. Individualized selection of different thrombus removal methods based on the pathogenesis can improve the good prognosis rate of patients.

\section{Background}

The characteristics of acute cerebral infarction caused by intracranial large-artery occlusion include high morbidity, high disability rate and high mortality. The key to its early treatment is the rapid and efficient revascularization to recover cerebral perfusion [1]. Intravenous thrombolysis is currently a widely used treatment method, but due to its short window time, and low revascularization rate in intracranial large-artery occlusion [2], for interventional therapy in intracranial vessels, mechanical thrombectomy is better in the window time and revascularization rate than intravenous thrombolysis [3]. The methods of mechanical thrombectomy include stent thrombectomy, A Direct Aspiration First Pass Technique (ADAPT), and combination of stent and aspiration method (Solumbra).

ADAPT has been proved to a rapid and high-efficient revascularization technique. In 2014, Turk, et al reported that the successful rate of ADAPT was 75\%, and $65 \%$ of the patients reached thrombolysis in Cerebral Infarction (TICI) 3 Reperfusion Score, with an average revascularization time of 28.1 minutes, and the fastest one was 3 minutes [4]. In 2019 AHA/ASA Guidelines for the Early Management of Patients With Acute Ischemic Stroke, it is mentioned that for patients whose Modified Rankin Scale (MRS) score before stroke is 0-1, symptomatic occlusion of internal carotid artery or M1 occlusion of middle cerebral artery, $\geq 18$ years old, National Institute of Health Stroke Scale (NHISS) score $\geq 6$, Alberta Stroke Proram Earl CT Scoregy (ASPECTS) $\geq 6$, and be able to do femoral artery puncture within 6 hours of stroke, ADAPT is not worse than stent [5]. In a recent systematic retrospective study, which included 9127 patients who underwent mechanical thrombectomy of intracranial artery, it showed that the positive result (52\% vs. 48\%) and 3-month mortality (15\% vs. $19 \%$ ) of ADAPT and stent were similar [6]. The COMPASS study also showed that the improvement of patients' functions after ADAPT and stent were similar [7]. Therefore, both ADAPT and stent are safe and effective treatment methods in thrombectomy and revascularization of intracranial artery. However, which methods is more suitable for acute cerebral infarctioncaused by different pathogenesis is not known yet, and there are few studies about this topic.

The most widely used classification criterion of the pathogenesis of acute cerebral infarction is TOAST classification, in which the pathogenesis is categorized as main artery atherosclerosis-induced cerebral infarction, cardioembolism-induced cerebral infarction, small vessel occlusion- induced cerebral infarction, stroke of other clear etiologies, and stroke of undetermined causes [8]. In main artery atherosclerosis-induced cerebral infarction, the first step if the rupture of fatty plaques in the inner walls of the blood vessels, followed by aggregation and adhesion of platelet that trigger fibrinogen, thus the platelet trabecula will contain many fibrin and red blood cells (RBC) [9], which is the cause of the embolism. The characteristics of cardioembolism is that it contains more fibrin and platelet, and less RBC [10]. In small vessel occlusion, the embolism is mostly the body or the tail of the above two kinds of embolisms, thus are mixed thrombus or red thrombus. Therefore, it can be seen that in artery atherosclerosis-induced cerebral infarction, the embolisms stick tightly to the inner walls of the blood vessels, and it's very common that hemadostenosis exists at the same time, so using ADAPT cannot take out the embolisms successfully, thus stent is needed [11]. But for cardioembolism-induced cerebral infarction, the embolisms bind loosely to the inner walls of the blood vessels, so the suction catheter can reach the embolisms and then take them out. It's also reported that for cardioembolism-induced cerebral infarction, ADAPT is better than stent [12].

In this study, we explore the effect of pathogenesis-based individualized thrombectomy on treatment result and prognosis of acute intracranial large-artery occlusion, in order to provide suggestions for improvement of treatment and prognosis. 


\section{Methods}

\section{Subjects}

A total of 151 acute cerebral infarction patients who underwent interventional therapy in intracranial vessels in our hospital from Jan, 2018 to Nov, 2019 , were included in this study. Inclusion and exclusion criteria of interventional therapy in intracranial vessels were according to the 2018 Chinese Guidelines for the Early Interventional Therapy of Patients With Acute Ischemic Stroke [13]. The current study has been approved by the Ethics Committee of our hospital, and all patients signed written informed consent.

The patients treated in the time period of Jan, 2018 to Dec, 2018 were set as control group, and all were treated with stent thrombectomy. The patients treated in the time period of Jan, 2019 to Dov, 2019 were set as experimental group, and thrombectomy methods were selected according to their pathogenesis, medical history, clinical manifestations and cerebral angiography results. Details were as follows: If patients had auricular fibrillation, and the disease onset was very sudden, and cerebral angiography showed a cupping-like (flat head) shape in the occluded vessel, it was very likely to be embolism-induced cerebral infarction (Fig. 1A). For these patients, ADAPT was used for thrombectomy. If patients had progressive stroke without auricular fibrillation, and cerebral angiography showed rabbit tail sign, it was more likely to be atherosclerosis-induced cerebral infarction (Fig. 1B) and stent thrombectomy was used for these patients. Medical history, National Institute of Health Stroke Scale (NHISS) score at admission, the time between the end of arteriography and revascularization, number of thrombectomy, Modified Rankin Scale (MRS) score at 3 month and complications were collected and compared among the 3 groups.

\section{Revascularization of occluded vessels}

Arteriography was performed for figuring out the offending vessels and the compensation of the vessels, and interventional therapy was used in patients with good compensation of the offending vessels. The thrombectomy method was selected based on the arteriography results, whether hemadostenosis existed or not, as well as the pathogenesis (if combination of stent and aspiration method was used, the patients were categorized into the stent group). If the first thrombectomy was unsuccessful, a second thrombectomy or balloon dilatation was then performed for revascularization of the occluded vessels. After the vessels were opened, its blood flow was monitored for 20 minutes for evaluating the risk of re-blocking. For the re-blocking in those who had in situ hemadostenosis, balloon dilatation or stent angioplasty was also performed during the first thrombectomy.

\section{Evaluation of the revascularization of occluded vessels}

$\mathrm{TICl}$ Reperfusion Score was used to evaluate the revascularization of occluded vessels and their reperfusion after mechanical thrombectomy. 0 means no reperfusion and there was no forward flow in the distal end of the occluded vessel. 1 means a little reperfusion, and contrast agent can go through the occluded vessels but cannot fill their distal end. 2 means partial reperfusion, and contrast agent can fill the distal end of the occluded vessels at a low speed. $2 a$ means $₫ 2 / 3$ of the distal end of the occluded vessels were filled, $2 b$ means the distal end was completely filled at a speed lower than normal. 3 means the distal end was completely filled at a normal speed. $2 \mathrm{~b}$ and 3 were considered as successful revascularization of occluded vessels.

\section{Statistical analysis}

SPSS 20.0 was used for statistical analysis. Rank sum test was used to analyze the data that were not normally distributed. Categorical data were analyzed by chi-square test. $\mathrm{P}<0.05$ was considered statistically significant.

\section{Results}

\section{Baseline data}

As shown in Table 1, there was no significant difference in gender, age, complicating diseases, pathogenesis, offending vessels and NHISS score at admission among the three groups.

\section{Prognosis of the patients}

As shown in Table 2, the time between the end of arteriography and revascularization among the three groups was significantly different ( $P=0.002)$. When compared between each two groups, it can be seen that there was no significant difference between control group and stent group $(z=1.540$, $P=0.124)$, and between stent group and ADAPT group $(z=0.869 \mathrm{~m} \mathrm{P}=0.385)$, but there was significant difference between control group and ADAPT group ( $z=5.49$, $\mathrm{P}=0.000)$.

Patency rate after one thrombectomy among the three groups was significantly different among the three groups $(P=0.048)$. When compared between each two groups, it showed that there was no significant difference between control group and ADAPT group $\left(\chi^{2}=2.162\right.$, $\left.P=0.141\right)$, and between stent group and ADAPT group $\left(X^{2}=1.052, P=0.305\right)$, but there was significant difference between control group and stent group $\left(\chi^{2}=5.910, P=0.015\right)$.

Revascularization rate was not significantly different among the three groups $(\mathrm{P}=0.611)$. Positive prognosis rate was significantly different among the three groups $(\mathrm{P}=0.03)$, and it was higher in the two experimental groups than the control group, but there was no significant difference between stent group and ADAPT group $\left(\chi^{2}=001, P=0.982\right)$.

\section{Discussion}


The main causes of occlusion-induced cerebral infarction are atherosclerosis and cardioembolism as well as other causes. It has been reported that in China, atherosclerosis-induced cerebral infarction accounts for $46.6 \%$ of all cases, therefore atherosclerosis is considered the most commonly seen vasculopathy in cerebral infarction patients in China [14]. Atherosclerosis-induced cerebral infarction is mainly caused by in situ thrombus in the hemadostenosis vessel [15]. As reported in a previous research that only 15 out of 29 internal carotid artery occlusion patients were found to have thrombus in the retrieved stent after thrombectomy; no thrombus was found in other patients, even after multiple stent thrombectomies, which proves that thrombus is not often found in this type of cerebral infarction [16]. In another research, it was found that in acute intracranial artery occlusion caused by internal carotid atherosclerosis, stent thrombectomy was better than ADAPT in the time between the end of arteriography and revascularization and duration of operation, thus it was concluded that stent thrombectomy was better than ADAPT in this type of intracranial artery occlusion [17]. On the contrary, for embolism-induced cerebral infarction, researchers believed that ADAPT may be better than stent thrombectomy [18]. In the current study, we found that the time between the end of arteriography and revascularization was significantly shorter in ADAPT group than in control group, which proves that ADAPT is a better choice for embolism-induced cerebral infarction.

With the development of the materials of suction catheter, ADAPT has been improved from the initial direct contact with the thrombus, to the current negative pressure suction technique, which can just partially contact with the thrombus and also leave the suction catheter in the vessel for the second angiography and thrombectomy [18]. It was reported in a recent study that the successful rate of ADAPT was related to its angle toward the thrombus; when the angle was $\geq 125.5^{\circ}$, successful rate increased significantly, especially in the middle cerebral artery and basilar artery [19]. For thrombosis on the basis of hemadostenosis, the hemadostenosis vessels are in a cone-shape, making the vascular wall irregular, thus the suction catheter cannot contact the thrombus at an adequate angle, so stent is a better choice because stent can pass the hemadostenosis part and pull the thrombus outside of the vessel. In addition, in such circumstances, a stent angioplasty is performed at the same time, which can instantly restore the forward flow and shorten the revascularization time. Thrombolysis can also partially be achieved by the plasminogen ability of the blood that goes through the revascularized vessel. In this study, patency rate after one thrombectomy was significantly higher in stent group than the other two groups, which confirms this theory.

In this study, the time of the stent group was longer than the ADAPT group, but the positive prognosis rate of the two groups was similar, which could be due to the fact that for the atherosclerosis-induced cerebral infarction, it needs longer time to completely occlude the vessel, thus the collateral fractional flow was better than embolism-induced cerebral infarction [20].

The limitation of this study are such that it was a single-center study, and the sample size was not large enough. Therefore, we need more cases to analyze the effects of thrombectomy methods, pathogenesis and complicating diseases. And we also need to perform multi-center and large-sample clinical trials to evaluate the positive prognosis rate after mechanical thrombectomy, in order to establish a individualize thrombectomy method that can be better in treating cerebral infarction.

\section{Conclusions}

For embolism-induced cerebral infarction, using ADAPT technique can reduce the time of revascularization. For atherosclerosis-induced cerebral infarction, using stent can increase patency rate after one thrombectomy. Choosing the most adequate thrombectomy method based on pathogenesis can increase positive prognosis rate in acute intracranial large-artery occlusion patients.

\section{Abbreviations}

ADAPT: A Direct Aspiration First Pass Technique

TICl:thrombolysis in Cerebral Infarction

NHISS: National Institute of Health Stroke Scale

RBC: red blood cells

MRS: Modified Rankin Scale

\section{Declarations}

\section{Ethics approval and consent to participate}

This study was conducted in accordance with the Declaration of Helsinki and approved by the ethics committee of Peking University First Hospital.

\section{Consent for publication}

Not applicable.

\section{Availability of data and materials}

All data generated or analyzed during this study are included in this published article 
All of the authors had no any personal, financial, commercial, or academic conflicts of interest separately.

\section{Funding}

Not applicable.

\section{Authors' contribution}

Conception and design of the research: Liu YC. Acquisition of data: Zheng MM, Li Y. Analysis and interpretation of the data:Liu YC, Xie SW. Statistical analysis :Liu QR. Obtaining financing : None. Writing of the manuscript : Liu YC, Wang JY. Critical revision of the manuscript for intellectual content : Li SR.All authors read and approved the final version of the manuscript

\section{References}

1. Goyal M, Menon BK, Van ZwamWH, et al. Endovascular Thrombectomy after Large- vessel Ischaemic Stroke[J]. Lancet, 2016, 387( 10029) : 17231731.

2. Vargas J, Spiotta AM, Fargen K, Turner RD, Chaudry I, Turk A. Experience with A Direct Aspiration First Pass Technique (ADAPT) for Thrombectomy in Distal Cerebral Artery Occlusions Causing Acute Ischemic Stroke. World Neurosurg, 2017;99:31-36.

3. SAVER J L, GOYAL M, BONAFE A, et al. StentRetriever Thrombectomy after Intravenous t-PA vs. t-PA Alone in Stroke[J]. N Engl J Med, 2015 , 372 \24『:2285-2295.

4. Turk A S , Frei D , Fiorella D , et al. ADAPT FAST study: a direct aspiration first pass technique for acute stroke thrombectomy[J]. Journal of Neurolnterventional Surgery, 2014, 6(4):260-264.

5. Powers WJ, Rabinstein AAA, Ckerson T, et al.Guidelines for the Early Management of Patients With Acute Ischemic Stroke: 2019 Update to the 2018 Guidelines for the Early Management of Acute Ischemic Stroke: A Guideline for Healthcare Professionals From the American Heart Association/American Stroke Association[J]. Stroke 2019; 50(12):e344-e418.

6. Primiani CT, Vicente AC, Brannick MT, Turk AS, Mocco J, Levy El, Siddiqui AH, Mokin M. Direct Aspiration versus Stent Retriever Thrombectomy for Acute Stroke: A Systematic Review and Meta-Analysis in 9127 Patients. J Stroke Cerebrovasc Dis. 2019;28(5):1329-1337.

7. Turk AS 3rd, Siddiqui A, Fifi JT, De Leacy RA, Fiorella DJ, Gu E, Levy El, Snyder KV, Hanel RA, Aghaebrahim A, Woodward BK, Hixson HR, Chaudry MI, Spiotta AM, Rai AT, Frei D, Almandoz JED, Kelly M, Arthur A, Baxter B, English J, Linfante I, Fargen KM, Mocco J. Aspiration thrombectomy versus stent retriever thrombectomy as first-line approach for large vessel occlusion (COMPASS): a multicentre, randomised, open label, blinded outcome, noninferiority trial. Lancet. 2019;393(10175):998-1008.

8. Mcardle PF , Kittner SJ , Ay H, et al. Agreement between TOAST and CCS ischemic stroke classification: the NINDS SiGN study[J]. Neurology, 2014, 83(18).=

9. Qazi EM, Sohn SI, Mishra S, Almekhlafi MA, Eesa M, d'Esterre,CD, et al. Thrombus characteristics are related to collaterals and angio-architecture in acute stroke. Can J Neurol Sci. 2015;42:381-388.

10. Sporns PB, Hanning U, Schwindt W, Velasco A, Minnerup J, Zoubi T, Heindel W, Jeibmann A, Niederstadt TU. Ischemic Stroke: What Does the Histological Composition Tell Us About the Origin of the Thrombus? Stroke. 2017;48(8):2206-2210.

11. Kang DH, Kim YW, Hwang YH, Park SP, Kim YS, Baik SK. Instant reocclusion following mechanical thrombectomy of in situ thromboocclusion and the role of low-dose intra-arterial tirofiban. Cerebrovasc Dis. 2014;37(5):350-355.

12. Gory B, Armoiry X, Sivan-Hoffmann R, Piotin M, Mazighi M, Lapergue B, Blanc R, Turjman F. A direct aspiration first pass technique for acute stroke therapy: a systematic review and meta-analysis. Eur J Neurol. 2018 Feb25(2):284-292.

13. Martin K, Beyer-Westendorf J, Davidson BL, Huisman MV, Sandset PM, Moll S. Use of the direct oral anticoagulants in obese patients: guidance from the SSC of the ISTH. J Thromb Haemost. 2016;14(6):1308-13.

14. Wang Y, Zhao X, Liu L, Soo YO, Pu Y, Pan Y, et al.; CICAS Study Group. Prevalence and outcomes of symptomatic intracranial large artery stenoses and occlusions in China:the Chinese Intracranial Atherosclerosis (CICAS) study. Stroke邓2014;45:663-669.

15. Lee JS, Hong JM, Kim JS. Diagnostic and therapeutic strategies for acute intracranial atherosclerosis-related occlusions. J Stroke 2017;19:143-151.

16. Yoon W, Kim SK, Park MS, Kim BC, Kang HK. Endovascular treatment and the outcomes of atherosclerotic intracranial stenosis in patients with hyperacute stroke. Neurosurgery 2015;76:680-686;

17. Kang DH, Yoon W. Current Opinion on Endovascular Therapy for Emergent Large Vessel Occlusion Due to Underlying Intracranial Atherosclerotic Stenosis. Korean J Radiol. 2019;20(5):739-748.

18. Alawieh A, Chatterjee AR, Vargas J, Chaudry MI, Lena J, Turner R, Turk A, Spiotta A. Lessons Learned Over More than 500 Stroke Thrombectomies Using ADAPT With Increasing Aspiration Catheter Size. Neurosurgery. 2020;86(1):61-70.

19. Bernava G, Rosi A, Boto J, et al. Direct thromboaspiration efficacy for mechanical thrombectomy is related to the angle of interaction between the aspiration catheter and the clot. J Neurointerv Surg. 2020;12(4):396-400.

20. Kim SJ, Ryoo S, Kim GM, Chung CS, Lee KH, Bang OY. Clinical and radiological outcomes after intracranial atherosclerotic stroke: a comprehensive approach comparing stroke subtypes.Cerebrovasc Dis 2011;31:427-434

Page 5/7 
Tables

Table 1. Baseline data

\begin{tabular}{|c|c|c|c|c|c|c|c|c|c|c|}
\hline \multirow[b]{2}{*}{$\begin{array}{l}\text { Group } \\
(\mathrm{N})\end{array}$} & \multirow[b]{2}{*}{$\begin{array}{l}\text { Gender } \\
\text { (male/female) }\end{array}$} & \multirow[b]{2}{*}{$\begin{array}{l}\text { Age } \\
\text { [average } \\
\text { (min, } \\
\text { max)] }\end{array}$} & \multicolumn{3}{|c|}{ Complicating diseases } & \multicolumn{2}{|c|}{ Pathogenesis } & \multicolumn{2}{|c|}{ Offending vessels } & \multirow{2}{*}{$\begin{array}{l}\text { NHISS } \\
\text { score at } \\
\text { admission }\end{array}$} \\
\hline & & & $\begin{array}{l}\text { Hypertension } \\
\text { (yes/no) }\end{array}$ & $\begin{array}{l}\text { Diabetes } \\
\text { mellitus } \\
\text { (yes/no) }\end{array}$ & $\begin{array}{l}\text { Atrial } \\
\text { fibrillation } \\
\text { (yes/no) }\end{array}$ & Embolism & $\begin{array}{l}\text { Non- } \\
\text { embolism }\end{array}$ & $\begin{array}{l}\text { Internal } \\
\text { carotid } \\
\text { system }\end{array}$ & $\begin{array}{l}\text { Vertebrobasilar } \\
\text { system }\end{array}$ & \\
\hline $\begin{array}{l}\text { Control } \\
\text { group } \\
\text { (53) }\end{array}$ & $32 / 21$ & $66(61,73)$ & $32 / 21$ & $14 / 39$ & $17 / 36$ & 33 & 20 & 45 & 8 & $19(15,22)$ \\
\hline $\begin{array}{l}\text { Stent } \\
\text { group } \\
(46)\end{array}$ & $32 / 14$ & $65(59,71)$ & $35 / 11$ & $13 / 33$ & $35 / 63$ & 52 & 46 & 38 & 8 & $17(14,22)$ \\
\hline \multirow{2}{*}{$\begin{array}{l}\text { ADAPT } \\
\text { group } \\
(52)\end{array}$} & $33 / 19$ & $\begin{array}{l}63(58 \otimes \\
72)\end{array}$ & $36 / 16$ & $20 / 32$ & & & & 34 & 18 & $20(15,22)$ \\
\hline & $\chi^{2}=926$ & $Z=1.59$ & $\chi^{2}=2.841$ & $\chi^{2}=2.030$ & $\chi^{2}=0.202$ & $\chi^{2}=1.184$ & & \multicolumn{2}{|l|}{$\chi^{2}=4.434$} & $\chi^{2}=9.74$ \\
\hline $\mathrm{P}$ & 0.629 & 0.125 & 0.242 & 0.362 & 0.653 & 0.227 & & \multicolumn{2}{|l|}{0.109} & 0.226 \\
\hline
\end{tabular}

Table 2. Prognosis of the patients

\begin{tabular}{|c|c|c|c|c|}
\hline Group (N) & $\begin{array}{l}\text { The time between the end of arteriography and revascularization } \\
\text { (minutes) [average (min, max)] }\end{array}$ & $\begin{array}{l}\text { Patency rate after one } \\
\text { thrombectomy }\end{array}$ & $\begin{array}{l}\text { Revascularization } \\
\text { rate }\end{array}$ & $\begin{array}{l}\text { MRS score at } \\
3 \text { month }<3\end{array}$ \\
\hline $\begin{array}{l}\text { Control } \\
\text { group (53) }\end{array}$ & $57(37,67)$ & $24 / 53$ & $50 / 53$ & $35 / 53$ \\
\hline $\begin{array}{l}\text { Stent group } \\
(46)\end{array}$ & $36(30 \rrbracket 50)$ & $32 / 46$ & $44 / 46$ & $39 / 46$ \\
\hline \multirow{3}{*}{$\begin{array}{l}\text { ADAPT } \\
\text { group (52) }\end{array}$} & $39(24,58)$ & $31 / 52$ & $51 / 52$ & $44 / 52$ \\
\hline & $\chi^{2}=12.96$ & $\chi^{2}=6.076$ & $\chi^{2}=6.076$ & $\chi^{2}=7.011$ \\
\hline & & & & 0.0010 .982 \\
\hline $\mathrm{P}$ & 0.002 & 0.048 & 0.611 & 0.03 \\
\hline
\end{tabular}

Figures 

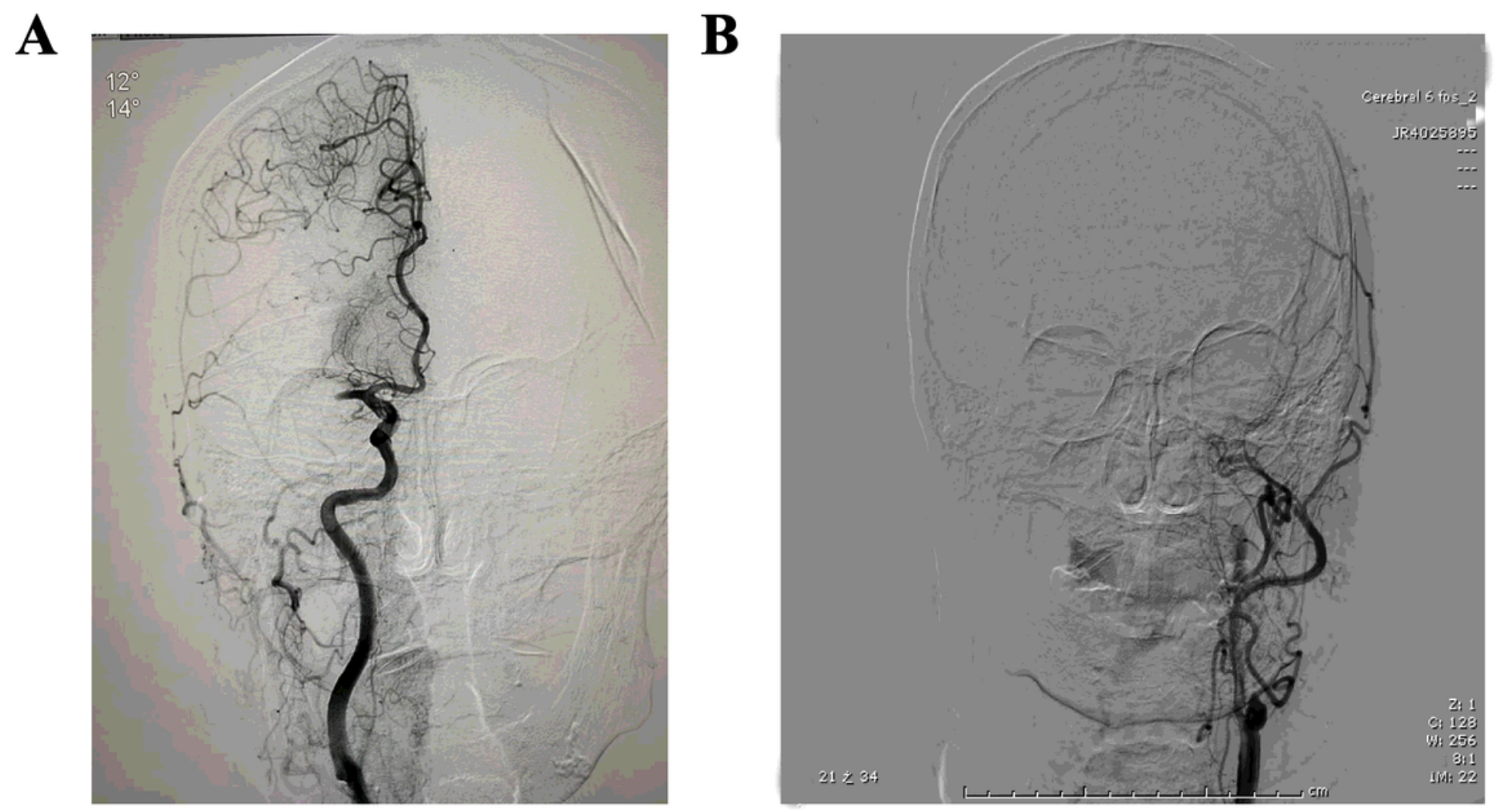

\section{Figure 1}

A. M1 occlusion of the middle cerebral artery cause by embolism. B. Occlusion of the initial segment of the internal carotid caused by atherosclerosis. 